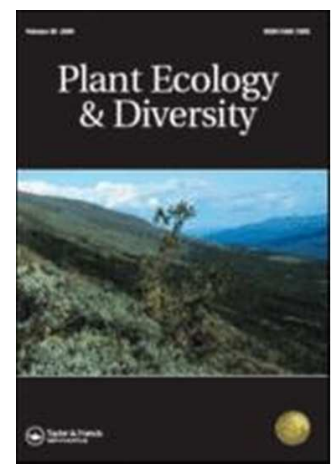

\title{
Transplanting the leafy liverwort Herbertus hutchinsiae: A suitable conservation tool to maintain oceanic-montane liverwort-rich heath?
}

\begin{tabular}{|r|l|}
\hline Journal: & Plant Ecology \& Diversity \\
\hline Manuscript ID & TPED-2015-0097.R2 \\
\hline Manuscript Type: & Original Article \\
\hline Keywords: & $\begin{array}{l}\text { bryophytes, assisted colonisation, reintroduction, population reinforcement, } \\
\text { dispersal limitation }\end{array}$ \\
\hline
\end{tabular}

\section{SCHOLARONE ${ }^{\mathrm{m}}$}

Manuscripts 
1 Abstract

2 Background: Translocating plants for conservation purposes can be a useful tool to enhance 3 existing populations, restore lost populations, or create new ones, but has rarely been done for 4 bryophytes, especially liverworts.

5 Aims: Here, the leafy liverwort Herbertus hutchinsiae, a representative species of oceanic6 montane liverwort-rich heath, was translocated to unoccupied habitat within its current range, 7 to establish whether its restricted distribution is due to habitat- or dispersal limitation.

8 Methods: Feasibility of establishing new populations outside the current distribution range 9 was assessed, to test the suitability of the species for assisted colonisation. Furthermore, 10 transplants were grown at degraded sites where the species had declined to assess potential 11 for restoration.

12 Results: Although maximal growth rates occurred within-range, transplants grew at all sites, 13 indicating that the species could be dispersal limited; a conclusion supported by distribution 14 modelling.

15 Conclusions: Assisted colonisation is thus an option for this species to overcome dispersal 16 limitation and to track future climate space. Reinforcement of populations at degraded sites is 17 only recommended if the pressure causing the degradation has been removed. These findings 18 provide an evidence base for practical conservation management.

19 Keywords: assisted colonisation, bryophytes, dispersal limitation, population reinforcement, 20 reintroduction. 


\section{1 Introduction}

22 Environmental change alters plant communities (e.g., Stevens et al. 2004; Smart et al. 2006), 23 with climate change being a major issue in global biodiversity changes (Hannah et al. 2007), 24 but other environmental drivers also playing their part. While the overall climate in British 25 Isles has become warmer and wetter (Barnett et al. 2006), the vegetation of the UK uplands 26 (all areas above enclosed farmland and generally above ca. $300 \mathrm{~m}$ a.s.1.) has also been 27 subjected to overgrazing, anthropogenic burning and atmospheric deposition of nitrogen and 28 sulphur (Barnett et al. 2006; RoTAP 2012). When these interacting drivers cause habitat 29 degradation and fragmentation, this can have very negative effects on some species, 30 particularly specialist species with low dispersal and colonisation abilities (Travis 2003) and 31 species populations with low genetic diversity that may not be able to adapt to environmental 32 changes in situ (Skelly et al. 2007).

33 Translocation (hereafter transplantation) may offer a management opportunity for these 34 specialist species to aid their dispersal, increase existing populations or treat inbreeding 35 depression ('reinforcement': IUCN/SSC 2013), and also to 'reintroduce' a species to areas 36 within its range where it previously existed but has disappeared (IUCN/SSC 2013). More 37 recently, the concept of moving species beyond their current range to reach future suitable 38 climate space or enhance their ability to reach such space by overcoming dispersal barriers, 39 has been debated as a potential conservation management tool (e.g., Brooker et al. 2011; 40 Hewitt et al. 2011). This process is known as assisted colonisation, amongst other names (see 41 IUCN/SSC 2013; National Species Reintroduction Forum 2014a,b). While the main benefits 42 are obviously the protection of biodiversity and prevention of extinction, concerns include 43 species becoming invasive out of their known range, the impact on donor populations and the 44 use of assisted colonisation as a substitute for other conservation efforts (Hewitt et al. 2011; 45 IUCN/SSC 2013). There is clearly a need for research in this area, for example there is a lack 46 of practical trials of transplant methods, specifically for species most likely to be impacted by 47 climate change (Brooker et al. 2011). Some bryophytes (mosses, liverworts and hornworts) 48 are vulnerable to environmental changes, e.g. pollution (Bates and Preston 2011) as they 49 often occupy patchy habitats, and consist of comparably small populations with restricted 50 dispersal abilities (Söderström and Herben 1997). 
51 Oceanic-montane liverwort-rich heath (hereafter 'liverwort heath' or 'the community') is a 52 plant community containing liverwort species likely to be impacted by environmental change 53 (Flagmeier et al. 2014). The community only occurs in the British Isles and Norway, with 54 Scotland being home to the most species-rich stands (Averis 1992; Paton 1999). Within the 55 National Vegetation Classification (NVC; Rodwell 1991), liverwort heath is classified as 56 Calluna vulgaris-Vaccinium myrtillus-Sphagnum capillifolium heath, Mastigophora woodsii57 Herbertus aduncus subsp. hutchinsiae sub-community (H21b) and the Vaccinium myrtillus58 Racomitrium lanuginosum heath, Bazzania tricrenata-Mylia taylorii sub-community (H20c). 59 It is characterised by a leafy liverwort-rich understore. Some of the liverworts also occur 60 outside Europe, and show remarkable disjunct distributions between north-western Europe 61 and north-western North America and/ or the Himalayas and western China (Hill et al. 1991). 62 The narrow geographic distribution of the component leafy liverwort species, and their restriction to oceanic-montane areas, may make them particularly sensitive to climate change. They are also severely impacted by habitat changes, mainly those involving loss of shelter, like removal of dwarf shrubs or those of trampling by herbivores, which promote grass overgrowth. All of these threats have been linked to observed liverwort declines in Scotland (Flagmeier et al. 2014) and in Ireland (Holyoak 2006).

68 69

The distribution of liverwort heath is limited to areas with an oceanic climate with high rainfall (at least 220 rain days a year with $>1 \mathrm{~mm}$ rain per day) and even temperatures, which is amplified by topography such as north- to east-facing mountain slopes and glacial corries (Ratcliffe, 1968). However, the community seems to be much less widespread in Scotland than would be expected from these climatic requirements. Distribution modelling, based on climatic and topographic variables, has demonstrated that even in areas in Scotland and Ireland which have apparently suitable conditions, fewer of the component liverwort species than predicted occur (Averis 1992; Hodd et al. 2014). Several reasons for this were suggested. First, the species could be under-recorded, especially in remote areas; in the last decade, more records have been added (Hill et al. 2008), but these liverworts have still not been observed at some sites, despite their apparent suitability in terms of climate and/or habitat requirements. Second, the liverworts have never been outside their present ranges, which actually represent their climatic range limits. Finally, the community has once been more widespread, but has since declined due to multiple and interactive drivers of environmental change including the practice of burning as well as sheep and deer grazing, both of which result in a loss of dwarf shrubs as shelter for the liverworts (Averis 1992; 
84 Averis 1994; Flagmeier et al. 2014). It has long been suggested that overgrazing and burning 85 may be responsible for the restricted distribution of these specialist liverwort species 86 (McVean and Ratcliffe 1962; Ratcliffe 1968; Birks 1973; Hobbs 1988; Rodwell 1991; Averis 87 1992), and some sites have been lost and/or damaged in Scotland (Hobbs 1988) as well as in 88 Ireland (Holyoak 2006).

The ability of these liverworts to re-colonise lost habitat or establish new populations is unpredictable as they have not been observed to produce spores in the British Isles (Hill et al. 1991), and most of them do not develop specialised propagules (Paton 1999). They are able to regenerate from vegetative fragments (Flagmeier et al. 2013), but it is unclear how far these can travel; it seems unlikely that they travel far in mountain terrain (Averis 1994). In summary, it is possible that additional suitable sites in terms of habitat and climatic conditions exist, but these sites have not been colonised by the liverworts due to their restricted dispersal ability. Furthermore, some sites where the liverwort heath has existed in the past have been environmentally degraded. It remains unclear whether these sites could sustain populations, should liverwort propagules arrive there.

Transplantation of bryophytes as whole plants or fragments has been successfully tested for habitat restoration and other conservation purposes, including population maintenance. Gunnarsson and Söderström (2007) demonstrated the potential of transplanting Sphagnum angermanicum to new sites in Sweden with highest establishment rate from whole shoots. Kooijman et al (1994) re-introduced Scorpidium scorpioides from Ireland to sites in the Netherlands where the species had disappeared, and Rothero et al (2006) augmented the only British population of Bryum schleicheri var. latifolium with material derived from ex situ cultivation. Establishment of transplants from moss fragments has been successful in 107 restoration experiments (Graf and Rochefort 2010; Aradottir 2012; Jeschke 2012). Overall 108 however, there have been fewer transplant studies for bryophytes than for higher plants 109 (Brooker et al. 2011).

To evaluate whether transplantation is a possible conservation tool for the liverworts of the liverwort heath, Herbertus hutchinsiae (Gottsche) A. Evans (Evans 1917), was chosen for a transplantation experiment and transplanted to areas within its current distribution where it 113 has declined ('reinforcement'), and to suitable habitat within the current distribution, but 114 where the species is not present e.g. due to dispersal limitation ('empty' localities cf. 
115 Söderström and Herben, 1997). At the same time, the potential for assisted colonisation was 116 tested by transplanting the species outside its current distribution range. Dispersal limitation 117 of this species was also investigated by species distribution modelling, to enable comparison 118 of climatically suitable land with current species occurrence. The following questions were 119 addressed: (1) How do transplants of H. hutchinsiae grow (a) in suitable habitat within its 120 current distribution, (b) in suitable habitat outside its current distribution, and (c) at degraded 121 sites where it was once more widespread but has declined? (2) Which environmental factors 122 influence $H$. hutchinsiae growth from transplants?

\section{Materials and methods}

The species

Herbertus hutchinsiae is an uncommon species in the British Isles (nationally scarce: occurring in fewer than 100 hectads (10 km squares)), and a European endemic. Outside the

British Isles, it only occurs in Norway. Neither male plants nor sporophytes have ever been observed, and it is assumed that it does not reproduce sexually. The species occurs on shaded mountain slopes in north- or east-facing corries, cliffs and boulder fields and can also be found in montane woods and ravines. H. hutchinsiae is a representative and relatively

132 frequent species of the liverwort heath community and was chosen in order to test the 133 transplantation method without affecting the source populations of the rarer species. 134 However, despite being locally abundant, its distribution is 'curiously patchy' (Hill et al. 135 1991), and it is absent from apparently suitable hills (Hill et al. 1991; Averis 1992).

\section{Study area}

137 The study was carried out in the Highlands of Scotland. Nine transplant sites were selected, 138 each belonging to one of three categories: (1) sites within the current distribution of $H$. 139 hutchinsiae, where populations are close-by, but where the species is not present (category 140 1); (2) sites outside the current distribution of $H$. hutchinsiae (category 2); and (3) sites where $141 H$. hutchinsiae is present but was once more widespread and has apparently declined due to 142 habitat degradation (category 3). The sites in categories 1 and 2 were chosen by examination 
143 of distribution data in the National Biodiversity Network Gateway (https://data.nbn.org.uk/),

144 to select those hectads which had records for $H$. hutchinsiae (category 1), and hectads 145 adjacent to category 1 hectads without $H$. hutchinsiae records (category 2). Possible 146 transplant sites within these areas were then chosen by consulting topography maps to select 147 north-facing slopes between 200 and $600 \mathrm{~m}$ altitude. The two degraded sites within the 148 currently known distribution of $H$. hutchinsiae (category 3) were selected on the basis of 149 expert advice (G. Rothero pers. comm.) and reports (Averis 1991a; Horsfield 2006). All sites 150 were visited prior to the experiment to confirm the suitability of the habitat for 151 transplantation, i.e. presence of dwarf shrubs and/or large boulders for shelter. The selection 152 process resulted in nine transplant sites (Figure 1), with four sites in category 1, three in 153 category 2 , and two in category 3 (Table 1 ).

154

155

156

157

158

159

160

161

162

163

164

165

166

167

168

169

170

171

172

173

\section{Transplant growth assessment}

Herbertus hutchinsiae was collected in June 2010 from one site where the species is abundant, the north-facing slopes of Liathach, a mountain in the north-west of Scotland (OS grid reference NG 948 588). Each transplant comprised of a bundle of shoots of ca. $5 \mathrm{~cm}$ diameter and $10 \mathrm{~cm}$ length. The transplants were taken off the hill, weighed, and kept in plastic bags (stored cool) until being transplanted up to one week after collection. Reference samples were also collected (see below).

Before weighing, transplant and reference samples were left to air-dry and equilibrate with ambient humidity at $\sim 20{ }^{\circ} \mathrm{C}$ in the laboratory for $12 \mathrm{~h}$. This amount of time was deemed appropriate for air-drying without killing the samples. Even though leafy liverworts are thought to be sensitive to drying out, experiments on $H$. hutchinsiae and several other leafy liverworts of the community showed that they can survive some drought as measured by percentage of cells alive post-treatment (Clausen, 1964), and also recover from drought (measured by carbon dioxide exchange), even after several days of air-drying (Averis 1994).

The air-dried samples were weighed, and the reference samples were then oven dried at $60{ }^{\circ} \mathrm{C}$ for $24 \mathrm{~h}$ and weighed again. Transplant growth was assessed as change in oven-dried biomass after estimating the initial oven-dry weight using an air-dried:oven-dried weight ratio obtained from the reference samples as e.g. in McCune et al (1996) and Muir et al (2006). At the end of the experiment, stems that had grown through the garden netting in which the transplants were wrapped, were counted (see below), as an additional indicator of growth. 
175 Each bundle of $H$. hutchinsiae was wrapped in garden netting and then pegged into the 176 vegetation with plastic-coated wire. At each transplant site, 30 transplants were placed within 177 a marked out area of about $40 \mathrm{~m}$ x $40 \mathrm{~m}$ on a mountain slope with dwarf-shrub cover. Each 178 transplant was pegged into the vegetation within an individual $25 \mathrm{~cm} \mathrm{x} 25 \mathrm{~cm}$ plot, with four 179 corners marked with garden pegs to aid re-location. The transplants were placed out in June 1802010 and left an average of 424 days on site. Control transplants were established at the 181 donor site in the context of a parallel study investigating suitable microhabitats, and they all 182 grew.

\section{Environmental variables}

184

At each plot, information on the (micro-)environment was recorded by assessing the vegetation cover of dwarf-shrubs, graminoids (grasses, sedges and rushes) and bryophytes (mainly mosses). From this information each plot was later attributed to one of three microhabitat categories dominated by dwarf-shrubs, grasses or mosses. Mean vegetation height $(\mathrm{cm})$ at eight localities surrounding the transplant plot was measured as a proxy for shelter. Presence of other liverworts of the community in the plots was also noted. At the end of the experiment any factors that could influence the growth of the transplants were recorded, e.g. the presence of algae on the liverworts and whether the transplant was partly overgrown by other plants or covered by plant litter.

For each site, climate (weather) information was collected. Rainfall data (average daily rainfall and number of rain days) for the duration of the experiment from the closest weather station for each site was obtained from the UK Met Office MIDAS dataset (UK Meteorological Office, 2012). Furthermore, three temperature data loggers were placed at each site to obtain a local measurement of temperature every $4 \mathrm{~h}$ as spot measurements. The data were used to calculate maximum, minimum and average temperature over the experimental period as well as the average temperature for February and July representing the winter and summer temperatures. A measure of relative oceanicity was calculated (Averis 1991b), as the number of rain days (> $0.1 \mathrm{~mm}$ precipitation) during the experimental period divided by the difference between the highest and lowest monthly mean daily temperatures in ${ }^{\circ} \mathrm{C}$. 
204

205

206

207

208

209

210

211

212

213

214

215

216

217

218

219

220

221

222

223

224

225

226

227

228

229

230

231

232

233

Data analysis

Data were analysed using the software package SPSS version 19 (SPSS 2010). The data on biomass change of the transplants were normally distributed with equal variances. Transplants with negative growth rates were kept in the analyses, ensuring that estimates of growth were conservative and also more realistic as they included losses of material from transplants. We used a two-tailed, paired t-test to test the null hypothesis that transplant biomass had not changed over the experimental period.

To test the differences in biomass change (hereafter also 'growth') between site categories, a general linear model (ANCOVA) was applied. The initial biomass of the transplants was included as a covariate to account for any influence of the starting weight on growth. This seemed to have an influence, therefore the relationship between the starting weight of a transplant and the growth response was investigated. The initial ANCOVA model included an interaction term (site category $\mathrm{x}$ initial biomass), but this was not significant, i.e. the relationship between final and initial weight did not differ between the three site categories, and so the interaction term was removed. The residuals of the model were checked for normality and equality of variance, and also for differences between sites. There was no effect of site on the residuals, therefore site was not used as a block in the model. A Sidak correction post-hoc test, suitable for investigating ANCOVA results (Field 2013), was applied to compare the differences in growth between site categories. To investigate the growth of transplants relating to their microhabitats the same model construction was used, with microhabitat category instead of site category. The number of branches (count data) between site categories was analysed using a generalised linear model (GLM) with a Poisson log-link function and subsequently compared with a Sidak post-hoc test.

Environmental variables (see above) were also compared between site categories. As the variables did not fulfil ANOVA assumptions, a non-parametric Kruskal-Wallis test was used followed by Mann-Whitney test with Bonferroni correction where effects were detected. The presence-absence variables 'presence of other liverworts', 'algae', 'overgrowth' and 'plant litter' were analysed by calculating the proportions of plots at each site with presence of the respective variable. From this, the mean value of each variable was compared between site categories as for the other environmental variables. 
234 To assess the influence of environmental variables on transplant growth, the relationships 235 between the environmental variables were first investigated with Pearson's correlation tests. 236 Many variables were correlated (e.g. average temperature and maximum temperature, 237 average rainfall and number of rain days) and thereafter only one representative of each 238 group of correlated variables was retained in further analysis. This left four explanatory 239 environmental variables, two describing the climate (oceanicity and mean temperature in 240 July), and two representing the vegetation (cover of grasses and mean vegetation height).

241 These variables were used in multiple linear regression, with a forward selection and 242 backwards elimination stepwise regression to identify the best model. The optimal model was 243 identified with the highest $\mathrm{R}^{2}$ in which all independent variables with $P>0.25$ were removed.

244 The influence of the presence-absence environmental variables (see above) on growth were 245 investigated using a Mann Whitney test.

\section{Species distribution modelling using occurrence and bioclimatic variables}

Modelling suitable niches enables identification of mismatches between the model and the actual current distribution, which reflect dispersal limitation. It is also a powerful tool in conservation activities for identifying suitable areas of habitat for a species. We investigated whether or not there are climatic limitations to the occurrence of $H$. hutchinsiae in large, currently unoccupied areas in Ireland and Scotland, by generating species distribution models. Presence data with resolution of 1-km or higher were used, and as predictors a set of uncorrelated bioclimatic variables were obtained from www.worldclim.org: annual mean temperature (bio1), mean diurnal range (bio2), temperature annual range (bio7), annual precipitation (bio12), and precipitation seasonality (bio15). Niche models were constructed setting several parameters to default ('auto features', convergence $=10^{-5}$, maximum number of iterations $=500)$, while varying the prevalence $(0.5,0.6$ and 0.7$)$ and regularisation value (1,2 and 3) to determine which combination of settings generated the best outcomes while minimizing the number of model parameters, as well as producing 'closed', bell-shaped response curves guaranteeing model transferability. As geographic background, we fitted a third-degree Trend Surface Analysis (TSA), and extracted 5000 points from the area with TSA values equal or higher than the lowest TSA value observed in a presence; this area additionally represents a well-recorded territory for bryophytes, and thus we combined recommendations by Acevedo et al (2012) and Anderson and Raza (2010). Performance of 
265 the model was assessed by means of the AUC in a ROC statistic through 10-fold cross266 validation.

\section{Results}

269 Of the 270 transplanted bundles, 268 (99\%) were re-located at the end of the experiment. 270 The primary question driving this study was to determine whether bundles of $H$. hutchinsiae 271 transplanted to other sites could survive and grow there. There was, indeed, significant 272 growth at each site in all site categories (Table 2; Figure 2). The mean transplant biomass 273 across all sites increased significantly over the duration of the experiment by $22 \%(t=-15.32$, $274 \mathrm{df}=267, P<0.001$ ), from a mean oven-dry mass of $4.28 \pm 0.07$ to $5.24 \pm 0.06 \mathrm{~g}$ dry mass, 275 with individual site mean biomass increases ranging from $8 \%$ to $45 \%$. Of the 268 transplants 276 over the nine sites, 39 samples (15\%) had negative biomass change, the greatest loss being $2772.6 \mathrm{~g}(45 \%)$. On average, 10 shoots were counted growing through the netting of each 278 transplant, the number of shoots growing though varied from 0 to 95 in a single transplant.

279 There was a significant negative relationship between the initial transplant weight and the 280 absolute growth response (Figure 3), indicating that small transplants grew better than big 281 ones. Controlling for this effect by using initial weight as a covariable in ANCOVA, growth 282 differed significantly between site categories $\left(F_{2,264}=4.90, P=0.008\right.$; Figure 2$)$, but not 283 between microhabitats (data not shown). The Sidak-corrected post-hoc comparison showed 284 that there was significant difference in growth between sites within the current range and both 285 the sites outside the range $(P=0.030)$ and the sites at which the species has declined $(P=$ 286 0.027). The sites outside the current range and the sites at which the species has declined did 287 not differ significantly in growth $(P=0.978)$. The number of new branches also differed 288 significantly between site categories $(P<0.001)$, but in contrast to the biomass results, 289 transplants at sites within the current range of $H$. hutchinsiae had fewer branches $(8.55 \pm$ $2900.27 ; P<0.05)$ than those at sites outside the range $(10.89 \pm 0.35)$ or at damaged sites $(9.93 \pm$ $2910.41)$.

292 Some environmental variables differed between site categories (Table 3), namely the cover of 293 dwarf shrubs was highest at sites within the current range of $H$. hutchinsiae, whilst the cover 
294 of grasses was highest at degraded sites. Only vegetation height differed among all site

295

296

297

298

299

300

301

302

303

304

305

306

307

308

categories (Table 3), with mean vegetation height highest at the sites outside the current range (category 2; $22.8 \pm 0.8 \mathrm{~cm}$ ), followed by sites within the current range (category 1) and damaged sites (category 3).

Transplant growth showed weak linear relationships with three continuous environmental variables; a positive relationship with oceanicity $\left(\mathrm{y}=-0.890+0.141 \mathrm{x} ; P=0.022 ; \mathrm{r}^{2}=\right.$ $0.036)$, and negative relationships with mean July temperature $(\mathrm{y}=2.580-0.148 \mathrm{x} ; P=$ $\left.0.021 ; \mathrm{r}^{2}=0.02\right)$ and cover of grasses $\left(\mathrm{y}=1.135-0.008 \mathrm{x} ; P=0.030 ; \mathrm{r}^{2}=0.02\right)$, but no relationship with vegetation height. However, when all these variables and initial weight were used as predictors of growth in a stepwise multiple linear regression, the best model $\left(\mathrm{F}_{2,265}=66.15, P<0.005\right)$ included only initial weight and mean July temperature, which explained $33 \%\left(\mathrm{R}^{2}=0.333\right)$ of the variation in growth (biomass change $=4.21-0.492$ initial weight - 0.104 mean July temperature). None of the variables measured as presence-absence (other liverworts, algae, overgrowth or plant litter) influenced growth significantly.

The best and least complex distribution model obtained with TSA background (Figure 4; beta multiplier $=2$, prevalence $=0.5$ ) had a test AUC value of $0.948 \pm 0.008$. The current distribution of $H$. hutchinsiae is narrower than the climatically suitable land estimated by the model in Scotland, suggesting that the liverwort could occur in several locations where it is apparently absent.

\section{Discussion}

Is the distribution of Herbertus hutchinsiae limited by habitat availability?

This study has shown that it is possible to successfully transplant bundles of the liverwort $H$. hutchinsiae to new sites, where it can continue to grow. There was no indigenous $H$. hutchinsiae present at most of these transplant sites; neither does the species occur in large areas of the British Isles and Scandinavia predicted to be suitable (Figure 4). Such mismatch could be the consequence of generating models without variables that would be important at finer scales, such as microtopography, due to the problems of obtaining such data. Despite 
322 this, the overall current range of $\mathrm{H}$. hutchinsiae matches the distribution of the most suitable 323 areas as predicted by the model quite well, but its occurrence at the local scale within that 324 range is very limited. Thus observations from both the field transplants and the model suggest 325 that $H$. hutchinsiae is dispersal limited rather than habitat limited, a conclusion which is 326 supported by the fact that this species has not been observed to produce spores in Scotland 327 and can only reproduce vegetatively. Spores tend to travel further than asexual propagules or 328 vegetative fragments (Laaka-Lindberg et al. 2003). Vegetative reproduction is thought to help 329 maintain local populations where sexual reproduction is rare or absent (e.g., Eckert 2001). 330 Therefore, dispersal limitation arising from the failure to produce sporophytes could be the 331 cause of the patchy distribution of $H$. hutchinsiae. Successful, yet rare, dispersal events 332 followed by its 'phalanx' strategy of clonal growth would explain why the species does not 333 fill the geographic area predicted suitable, and yet does cover relatively extensive areas in the 334 glacial corries where it does occur. In a meta-analysis of life-history characteristics, 335 population dynamics and habitat attributes of British bryophytes, Söderström and During 336 (2005) found that population characteristics linked to limited dispersal rather than habitat 337 limitations are often the cause for restricted distributions. This is indicated by the occurrence 338 of 'empty' localities or unoccupied habitat and can only be proven through transplantation 339 experiments (Söderström and During 2005), as in this study.

Transplanting Herbertus hutchinsiae to overcome dispersal limitation - site selection and 342 practical considerations

343 The transplants grew at all sites, but growth was higher at sites within the current range of $H$. 344 hutchinsiae than at sites either outside of the current range, or where the species has declined 345 due to some form of disturbance. This suggests that even though there were no strong links 346 with environmental variables, the environmental conditions at unoccupied habitat close to 347 extant populations are the most suitable. H. hutchinsiae also grew at sites outside its current 348 range and these sites may be at the climatic range limits of the species yet are able to support 349 its growth. This indicates that the species is limited in its dispersal ability, preventing 350 colonisation of these localities. Together with the sites within the current distribution this 351 represents a wide range of sites which are available for potential increase of the number of 352 populations. In contrast to the biomass results, transplants at sites within the current 
353 distribution of $H$. hutchinsiae had fewer branches than those at sites outside the distribution 354 or at damaged sites, indicating that regardless of differences in overall biomass increase, 355 growth responses such as expansion by branching is possible in all site categories.

When selecting sites for transplants it is important to consider not only broad-scale climatic conditions (e.g. in a 10-km square), but also local climate and habitat conditions, as these determine the survival and establishment of the transplants (Gunnarsson and Söderström 2007; Graf and Rochefort 2010). In this study, transplanted bundles of shoots grew independent of microhabitat type, only a very small negative influence of cover of grasses on growth was indicated. However, transplanted fragments of $H$. hutchinsiae have been shown to grow better between other bryophytes than in other microhabitats (Flagmeier et al. 2013).

Transplant bundle weight may also be important to transplantation success, as an unexpected effect of initial transplant weight on growth was observed in this study, suggesting that smaller transplants grew better than bigger transplants. Where $H$. hutchinsiae occurs it does so abundantly, building big orange cushions (Hill et al. 1991; Averis 1994). In fact, this species seems to fit the 'phalanx' strategy of clonal growth by which acrocarpous bryophytes form dense cushions as a 'physiologically integrated front', thereby preventing interspecific competition (Cronberg et al. 2006). These bryophytes also tend to carry resources from the mother plant as they expand by branching, and indeed $H$. hutchinsiae has a relatively high branch production (Flagmeier et al. 2013). Perhaps smaller transplants show greater growth because the species strategy is to initiate a higher growth response when less dense, to eventually build dense cushions e.g. to prevent water losses. Bigger transplants on the other hand may experience more self-shading, leading to shoot etiolation and consequently less biomass increase (Rydin 2009). The latter may also be exacerbated if shoots within large 
385 transplant bundles were packed at higher densities than would occur naturally. Although 386 generally, negative effects (decreased growth or increased mortality) with increasing shoot 387 density is common in vascular plants ('self-thinning rule', see Begon et al. 2006), this also 388 applies to some bryophytes. Negative effects of density were also observed on growth of 389 three mosses from fragments (Scandrett and Gimingham 1989), and on shoot recruitment in 390 Sphagnum, although in this case the phenotypic plasticity of the species allowed it to form 391 slender but tall (etiolated) shoots to escape burial by keeping their apex at the surface (Rydin 392 1995). This may have been the case for our bigger transplants, where shoots in the middle of 393 the transplants might have become more etiolated.

394 Generally, the use of relative growth rate or biomass increase rather than absolute biomass is 395 not seen as critical in bryophytes as shoot growth is independent of initial size (Rydin 2009), 396 but our observations show that it is worth double-checking for effects of initial size or mass 397 when transplanting bundles of shoots, as there could be growth responses related to shoot 398 density for species which show preference for growing in cushions, such as $H$. hutchinsiae.

\section{Transplanting Herbertus hutchinsiae - potential for restoration}

400 Both of the sites at which $H$. hutchinsiae has declined were within the current range of the 401 species, but the transplants at those sites grew less well than the ones within the current range 402 and close to extant, healthy populations. This indicates that the lower growth rate at sites of 403 historical decline is due to habitat conditions rather than wider climatic factors. One of these 404 sites, Ben More Coigach, has been subjected to burning and high deer numbers in the past 405 (Averis 1991a; Horsfield 2006), and the resulting habitat is of patchy dwarf-shrub heath, with 406 remnants of liverworts. Grazing also opens up the dwarf-shrub cover, and allows the invasion 407 of grasses (e.g., Hartley and Mitchell 2005). The damaged sites had overall more grass cover 408 than other sites (Table 3). Also, there are patches of bare ground covered by lichens (e.g. 409 Trapeliopsis pseudogranulosa) and algae (authors' pers. obs.). In fact, of all sites, Ben More 410 Coigach had most algae covered transplants (17 out of 36), suggesting that the algae from the 411 bare patches can spread onto transplants. Despite no statistical evidence that this affected 412 their growth (Mann Whitney test $P=0.14$ ), this is worth mentioning as it could affect 413 transplant growth over a longer period of time. The other site where liverwort heath has 414 declined, Glenfinnan, had H. hutchinsiae only as remnants on crags, supposedly also a result 415 of historical overgrazing of the surrounding vegetation leading to loss of Calluna vulgaris 
416 and subsequent decline in H. hutchinsiae. The site was fenced for woodland regeneration, and 417 there is presently abundant tree regeneration and rank Calluna and grasses. The vegetation is 418 however now so tall that competition, especially with grasses, may become a problem if 419 permanent transplants of $H$. hutchinsiae were to be attempted to enhance the existing 420 population. At a transplant site of Bryum schleicheri var latifolium in Scotland (Rothero et al. 421 2006), 40\% of transplants survived 2 years, but the site has since been invaded by the rush 422 Juncus acutiflorus, threatening the continued establishment of the moss (G. Rothero pers. 423 comm.). Competition from higher plants for resources (light, space) can therefore be 424 problematic. Former dwarf-shrub heaths that have been degraded by grazing or burning 425 should recover to a certain standard (e.g. with a minimum area of dwarf-shrub cover and 426 without obvious signs of trampling, but not under total absence of grazing), before attempting 427 the restoration or enhancement of liverwort populations (IUCN/SSC, 2013). Based on these 428 results, although transplanted $H$. hutchinsiae can grow at degraded sites, transplanting it to 429 these sites for restoration is less promising than protecting the current populations from future 430 damage.

432 Enhancing the current populations of $H$. hutchinsiae and/or creating new ones by moving the 433 species only within its range would negate the concerns raised by some (e.g., Hewitt et al. 434 2011) associated with moving a species outside of its current range. However, this study has 435 shown that $H$. hutchinsiae is a suitable species for assisted colonisation because it does not 436 give rise to the common concerns associated with that method (IUCN/SSC 2013; National 437 Species Reintroduction Forum 2014). H. hutchinsiae is locally frequent and can be grown ex 438 situ (Flagmeier et al. 2013), so that material for translocations does not need to affect source 439 populations (as done e.g., by Rothero et al. 2006). Furthermore, it is unlikely to become 440 invasive; the few reported bryophytes that have become invasive in Europe (reviewed in 441 Brooker et al. 2011) are mosses characterised by high spore and/or vegetative propagule 442 production. These features do not apply to $H$. hutchinsiae, and as shown here, its distribution 443 is restricted due to dispersal limitation in the first place. These conclusions may be applied to 444 the other liverworts of the liverwort heath as they are closely coexisting species with similar 445 characteristics and life history. 
446 However, before assisted colonisation is undertaken, one first needs to know if climate is the 447 main threat for the future persistence of this species. The liverworts that occur in liverwort 448 heath need a constant humid environment and frequent rainfall (Ratcliffe, 1968; Averis, 449 1994), which suggests that they are highly vulnerable to climate change (Hodd et al., 2014). 450 In the north-west Highlands of Scotland, liverwort heath flourishes in an oceanic climate with 451 a low annual temperature range (mean January temperature $3-4{ }^{\circ} \mathrm{C}$, mean July temperature $452<14{ }^{\circ} \mathrm{C}$ ) and high annual rainfall of $>1500 \mathrm{~mm}$ (Hill et al. 1991). This study found a 453 negative effect of an increase in average temperature in July on growth of the transplants and 454 this may manifest itself under future climate scenarios, as temperatures, particularly in 455 summer and autumn, are predicted to rise by up to $4.5^{\circ} \mathrm{C}$ over parts of north-west Scotland 456 by 2080 (medium emissions scenario, IPCC A1B) (UK Climate Projections 2009). In fact, 457 average spring, summer and winter temperatures have already risen by more than $1{ }^{\circ} \mathrm{C}$ since 458 1961, along with an average increase in winter precipitation of $60 \%$ for northern and western 459 Scotland, and drier summers (Barnett et al. 2006). Changes in seasonality and pattern of 460 rainfall are likely to be problematic for these species. Clearly, climate change is one of the 461 main threats for this oceanic-montane community, and has been implicated in changes in the 462 community over the last 50 years (Flagmeier et al. 2014).

463 The absence of sexual reproduction in the liverwort heath species may reduce genetic 464 variation and therefore evolutionary potential, resulting in less ability to adapt to 465 environmental change (Laaka-Lindberg et al. 2000), while their low dispersal ability means 466 that they will not be able to track any suitable climate space, whether along an elevation or 467 latitude gradient, and essentially become 'stranded'. Species distribution modeling for lichens 468 in the UK (Ellis et al. 2007) and oceanic-montane species including liverworts of the 469 liverwort heath in Ireland (Hodd et al. 2014), predict losses in southern ranges counteracted 470 by range expansion northwards. Given the dispersal limitation of the liverworts, they are 471 unlikely to reach this future climate space. Therefore, if conditions become unsuitable at 472 current sites under climate change, assisted colonisation to overcome dispersal limitation 473 provides a promising option to safeguard this internationally important community. However, 474 climate change is only potential threat to the liverworts today; they have declined due to 475 changes in habitat in Scotland (Ratcliffe 1968; Averis 1992; Flagmeier et al. 2014) as well as 476 Ireland (Holyoak 2006), linked amongst other factors, to overgrazing and burning. These 477 'manageable' threats should also be addressed and controlled in situ and complemented with 478 assisted colonisation to give the species a chance to persist as suitable climate space moves. 


\section{Conclusions}

480 Using suitable transplant methods, this study has shown that there are unoccupied sites 481 available for possible colonisation by $H$. hutchinsiae, and that transplanting this species can 482 help to overcome the barriers of dispersal limitation, given that climate and habitat 483 requirements are taken into account. The distribution modelling illustrated that habitat 484 limitation is unlikely to be the cause of the scarce distribution of this liverwort in Scotland. 485 Monitoring transplants over a longer period of time is essential to ensure that not only 486 growth, but also long-term establishment can take place. The new growth observed in the 487 form of shoots that had grown through the netting around the H. hutchinsiae bundles may be 488 an initial indication that there is potential for transplants to spread.

Transplantation of bryophytes for conservation purposes has mainly involved mosses (e.g., 490 Kooijman et al. 1994; Rothero et al. 2006; Gunnarsson and Söderström 2007). 491 Transplantation of the leafy liverwort Marchesinia mackaii to establish new populations 492 resulted in low survival of the plants (Geissler 1995). Dynesius (2012) successfully 493 transplanted three leafy liverworts not directly for conservation purposes, but in an 494 experiment on effects of ash on growth and survival of bryophytes. Therefore, this study 495 provides, to our knowledge, the first evidence for successful transplant of a leafy liverwort 496 for conservation purposes. It is likely that the other leafy liverworts of the liverwort heath 497 could also be transplanted by this method, although it should be tested individually on a small 498 scale to confirm this. This study demonstrated that $H$. hutchinsiae can grow in the field from 499 transplants of whole shoots, and of fragments (Flagmeier et al. 2013), and this, together with 500 the ability to select suitable habitat based on the known habitat requirements of the species, 501 provides an opportunity for practical conservation applications. These could include 502 enhancing extant populations and increasing the number of populations within the current 503 range to increase the resilience of the species, restoring populations that have declined over 504 the last half century (Flagmeier et al. 2014) and transplanting material to future suitable 505 climate space as an active conservation strategy to mitigate against liverwort heath species 506 becoming stranded without an effective mode of dispersal in future climate scenarios. 
509 Thanks to the relevant landowners and managers for permission to carry out the experiments,

510 Chris Preston for helping to obtain the liverwort distribution records and the distribution map,

511 Gordon Rothero and Dave Horsfield for advice on choosing experimental sites and Alex

512 Douglas for statistical advice. Juliane Geyer's help with fieldwork was greatly appreciated.

513 This study was made possible by a NERC PhD studentship and financial support from the

514 Royal Botanic Garden Edinburgh and Scottish Natural Heritage.

515

516

\section{References}

517 Acevedo P, Jiménez-Valverde A, Lobo JM, Real R. 2012. Delimiting the geographical 518 background in species distribution modelling. Journal of Biogeography 39:1383-1390.

519 Anderson RP, Raza A. 2010. The effect of the extent of the study region on GIS models of 520 species geographic distributions and estimates of niche evolution: preliminary tests with 521 montane rodents (genus Nephelomys) in Venezuela. Journal of Biogeography 37:13785221393.

523 Aradottir AL. 2012. Turf transplants for restoration of alpine vegetation: does size matter? 524 Journal of Applied Ecology 49:439-446.

525 Averis A. 1991a. Hepatic mats in north-west Ross and Sutherland: a comparison of Ben More 526 Coigach, Cul Mor and Quinag. Scottish Natural Heritage, Ullapool.

527 Averis A. 1992. Where are all the Hepatic Mat Liverworts in Scotland? Botanical Journal of 528 Scotland 46:191-198.

529 Averis ABG. 1991b. A survey of the bryophytes of 448 woods in the Scottish Highlands. 530 MSc, University of Reading, Reading.

531 Averis AM. 1994. The ecology of an Atlantic liverwort community. PhD, University of 532 Edinburgh, Edinburgh.

533 Barnett C, Perry M, Hossell J, Hughes G, Procter C. 2006. Patterns of climate trends across 534 Scotland: technical report. SNIFFER Project CC03. Scotland and Northern Ireland Forum 535 for Environmental Research, Edinburgh.

536 Bates JW, Preston CD. 2011. Can the effects of climate change on British bryophytes be 537 distinguished from those resulting from other environmental changes? In Bryophyte 538 ecology and climate change, Tuba Z, Slack NG, Stark LG, editors, pp. 371-407. 539 Cambridge University Press, Cambridge, UK. 
540 Begon M, Townsend CR, Harper JL. 2006. Ecology: From Individuals to Ecosystems, ed. 4. 541 Blackwell Science, Oxford.

542 Birks HJB. 1973. Past and present vegetation of the Isle of Skye. Cambridge University 543 Press, Cambridge.

544 Brooker R, Britton A, Gimona A, Lennon J, Littlewood N. 2011. Literature review: species 545 translocations as a tool for biodiversity conservation during climate change. Scottish 546 Natural Heritage, Inverness.

547 Clausen E. 1964. Tolerance of hepatics to desiccation and temperature. The Bryologist $548 \quad 67: 411-417$.

549 Cronberg N, Rydgren K, Økland RH. 2006. Clonal structure and genet-level sex ratios 550 suggest suggest different roles of vegetative and sexual reproduction in the clonal moss 551 Hylocomium splendens. Ecography 29:95-103.

552 Dynesius M. 2012. Responses of bryophytes to wood-ash recycling are related to their 553 phylogeny and $\mathrm{pH}$ ecology. Perspectives in Plant Ecology, Evolution and Systematics $554 \quad 14: 21-31$.

555 Eckert CG. 2001. The loss of sex in plants. Evolutionary Ecology 15:501-520.

556 Ellis CJ, Coppins BJ, Dawson TP, Seaward MRD. 2007. Response of British lichens to 557 climate change scenarios: trends and uncertainties in the projected impact for contrasting 558 biogeographic groups. Biological Conservation 140:217-235.

559 Evans AW. 1917. Notes on the genus Herberta, with a revision of the species known from 560 Europe, Canada and the United States. Bulletin of the Torrey Botanical Club 44:191-222.

561 Field A. 2013. Discovering statistics using SPSS: and sex and drugs and rock 'n' roll, ed. 4. 562 SAGE Publcations Ltd., London.

563 Flagmeier M, Long DG, Genney DR, Hollingsworth PM, Ross LC, Woodin SJ. 2013a. Fifty 564 years of vegetation change in oceanic-montane liverwort-rich heath in Scotland. Plant 565 Ecology and Diversity 7:457-470

566 Flagmeier M, Long DG, Genney DR, Hollingsworth PM, Woodin SJ. 2013b. Regeneration 567 capacity of oceanic-montane liverworts: implications for community distribution and 568 conservation. Journal of Bryology 35:12-19.

569 Geissler P. 1995. First experience with conservation of southern European bryophytes. $570 \quad$ Cryptogamica Helvetica 18:151-155.

571 Graf MD, Rochefort L. 2010. Moss regeneration for fen restoration: Field and greenhouse 572 experiments. Restoration Ecology 18:121-130. 
573 Gunnarsson U, Söderström L. 2007. Can artificial introductions of diaspore fragments work 574 as a conservation tool for maintaining populations of the rare peatmoss Sphagnum 575 angermanicum? Biological Conservation 135:450-458.

576 Hannah L, Midgley G, Andelman S, Araújo M, Hughes G, Martinez-Meyer E, Pearson R, 577 Williams P. 2007. Protected area needs in a changing climate. Frontiers in Ecology and the 578 Environment 5:131-138.

579 Hartley SE, Mitchell RJ. 2005. Manipulation of nutrients and grazing levels on heather 580 moorland: changes in Calluna dominance and consequences for community composition. 581 Journal of Ecology 93:990-1004.

582 Hewitt N, Klenk N, Smith AL, Bazely DR, Yan N, Wood S, MacLellan JI, Lipsig-Mumme 583 C, Henriques I. 2011. Taking stock of the assisted migration debate. Biological 584 Conservation 144:2560-2572.

585 Hill MO, Preston CD, Smith AJE. 1991. Atlas of the bryophytes of Britain and Ireland. 586 Volume I: Liverworts (Hepaticae and Anthocerotae). Harley Books, Colchester, Essex. 587 Hill MO, Blackstock TH, Long DG, Rothero GP. 2008. A checklist and census catalogue of 588 British and Irish bryophytes. British Bryological Society, Middlewich.

589 Hobbs AM. 1988. Conservation of leafy liverwort-rich Calluna vulgaris heath in Scotland. I590 In Ecological change in the uplands, Usher MB, Thompson DBA, editors, pp. 339-343. $591 \quad$ Blackwell Scientific, Oxford.

592 Hodd RL, Bourke D, Sheehy Skeffington M. 2014. Projected range contractions of european 593 protected oceanic montane plant communities: Focus on climate change impacts is $594 \quad$ essential for their future conservation. PLoS ONE, 9, e95147.

595 Holyoak DT. 2006. Progress towards a species inventory for conservation of bryophytes in 596 Ireland. Proceedings of the Royal Irish Academy 106B:225-236.

597 Horsfield D. 2006. Comparisons of assessments of the impacts of large herbivores on upland 598 habitats at Inverpolly, West Sutherland. In: Scottish Natural Heritage Commissioned 599 Report F01AC211. Scottish Natural Heritage Commissioned Report F01AC211, 600 Edinburgh.

601 IUCN/SSC. 2013. Guidelines for Reintroductions and Other Conservation Translocations. 602 Version 1.0. Gland, Switzerland: IUCN Species Survival Commission, viiii + 57 pp.

603 Jeschke M. 2012. Cryptogams in calcareous grassland restoration: perspectives for artificial 604 vs. natural colonization. Tuxenia 32:269-279. 
605 Kooijman AM, Beltman B, Westhoff V. 1994. Extinction and reintroduction of the bryophyte 606 Scorpidium scorpioides in a rich-fen spring site in the Netherlands. Biological 607 Conservation 69:87-96.

608 Köppen W. 1936. Das geographische System der Klimate. Gebrüder Borntraeger, Berlin.

609 Laaka-Lindberg S, Hedderson TA, Longton RE. 2000 Rarity and reproductive characters in 610 the British hepatic flora. Lindbergia 25:78-84.

611

Laaka-Lindberg S, Korpelainen H, Pohjamo M. 2003. Dispersal of asexual propagules in bryophytes. Journal of the Hattori Botanical Laboratory 93:319-330.

McCune B, Derr CC, Muir PS, Shirazi A, Sillett SC, Daly WJ. 1996. Lichen pendants for transplant and growth experiments. Lichenologist 28:161-169.

McVean DA, Ratcliffe DN. 1962. Plant Communities of the Scottish Highlands: A Study of Scottish Mountain, Moorland and Forest Vegetation. H.M.S.O., London.

Muir PS, Rambo TR, Kimmerer RW, Keon DB. 2006. Influence of overstory removal on growth of epiphytic mosses and lichens in Western Oregon. Ecological Applications 16:1207-1221.

National Species Reintroduction Forum. 2014a. The Scottish Code for Conservation Translocations. Scottish Natural Heritage.

National Species Reintroduction Forum. 2014b. Best Practice Guidelines for Conservation Translocations in Scotland Version 1.1. Scottish Natural Heritage.

Paton JA. 1999. The liverwort flora of the British Isles. Harley Books, Essex.

Phillips SJ, Anderson RP, Schapire RE. 2006. Maximum entropy modeling of species geographic distributions. Ecological Modelling 190:231-259.

Ratcliffe DA. 1968. An ecological account of Atlantic bryophytes in the British Isles. New Phytology 67:365-439.

Rodwell JS. 1991. British Plant Communities. Volume 2. Heaths and Mires. Cambridge University Press, Cambridge.

RoTAP. 2012. Review of Transboundary Air Pollution: acidification, eutrophication, ground level ozone and heavy metals in the UK. DEFRA, London.

Rothero GP, Duckett JG, Pressel S. 2006. Active conservation: augmenting the population of Bryum schleicheri var latifolium via in vitro cultivation. Field Bryology 90:12-16.

Rydin H. 1995. Effects of density and water level on recruitment, mortality and shoot size in Sphagnum populations. Journal of Bryology 18:439-453.

Rydin H. 2009. Population and community ecology of bryophytes. In Bryophyte biology, ed. 2, Goffinet B, Shaw AJ, pp. 393-444. Cambridge University Press, Cambridge. 
639 Scandrett E, Gimingham CH. 1989. Experimental investigation of bryophyte interactions on 640 dry heathland. Journal of Ecology 77:838-852.

641 Skelly DK, Joseph LN, Possingham HP, Freidenburg LK, Farrugia TJ, Kinnison MT, Hendry 642 AP. 2007. Evolutionary responses to climate change. Conservation Biology 21:1353-1355. 643 Smart SM, Thompson K, Marrs RH, Le Duc MG, Maskell LC, Firbank LG. 2006. Biotic 644 homogenization and changes in species diversity across human-modified ecosystems. 645 Proceedings of the Royal Society of London. Series B, Biological Sciences 273:26596462665.

647 Söderström L, Herben T. 1997. Dynamics of bryophyte metapopulations. Advances in 648 Bryology 6:205-240.

649 Söderström L, During HJ. 2005. Bryophyte rarity viewed from the perspectives of life history 650 strategy and metapopulation dynamics. Journal of Bryology 27:261-268.

651 SPSS. 2010. IBM SPSS Data Preparation 19. SPSS Inc., Chicago.

652 Stevens CJ, Dise NB, Mountford JO, Gowing DJ. 2004. Impact of nitrogen deposition on the 653 species richness of grasslands. Science 303:1876-1879.

654 Travis JMJ. 2003. Climate change and habitat destruction: a deadly anthropogenic cocktail. 655 Proceedings of the Royal Society of London. Series B, Biological Sciences 270:467-473.

656 UK Meteorological Office. 2012. Met Office Integrated Data Archive System (MIDAS) Land 657 and Marine Surface Stations Data (1853-current). Available at: 658 http://badc.nerc.ac.uk/view/badc.nerc.ac.uk_ATOM_dataent_ukmo-midas (accessed Jan 659 18st., 2013).

660 Webber BL, Yates CJ, Maitre DCL, Scott JK, Kriticos DJ, Ota N, McNeill A, Roux JJL, 661 Midgley GF. 2011. Modelling horses for novel climate courses: insights from projecting 662 potential distributions of native and alien Australian acacias with correlative and 663 mechanistic models. Diversity and Distributions 17:978-1000.

664

665 
Table 1. Parameters of sites selected for transplantation of Herbertus hutchinsiae at ... sites in north-west Scotland. Category 1, sites within species' current range; category 2, sites outside current range; category 3, sites where species has declined. Relative oceanicity was calculated after Averis (1991b), as the number of rain days ( $>0.1 \mathrm{~mm}$ precipitation) during the experimental period divided by the difference between the highest and lowest monthly mean daily temperatures in ${ }^{\circ} \mathrm{C}$. Associate liverworts: Ao, Anastrepta orcadensis; Bt, Bazzania tricrenata; Bp, Bazzania pearsonii; Hh, Herbertus hutchinsiae; Mt, Mylia taylorii; Mw, Mastigophora woodsii; Pc, Plagiochila carringtonii; Pp, Pleurozia purpurea; Sg, Scapania gracilis.

\begin{tabular}{|c|c|c|c|c|c|c|c|}
\hline Site name & $\begin{array}{l}\text { OS grid } \\
\text { reference }\end{array}$ & $\begin{array}{c}\text { Site } \\
\text { category }\end{array}$ & $\begin{array}{c}\text { Elevatio } \\
\mathbf{n}(\mathbf{m})\end{array}$ & $\begin{array}{l}\text { Slope } \\
\left({ }^{\circ}\right)\end{array}$ & $\begin{array}{c}\text { Annual mean } \\
\text { temperature } \\
\left({ }^{\circ} \mathrm{C}\right)\end{array}$ & $\begin{array}{l}\text { Oceanicity } \\
\text { index }\end{array}$ & $\begin{array}{l}\text { Associate } \\
\text { liverworts } \\
\text { present }\end{array}$ \\
\hline Cul Beag & NC163088 & 1 & 240 & 28 & 6.3 & 13.7 & $A o, B t, M t, P p, S g$ \\
\hline Creag Dubh & NH124615 & 1 & 460 & 33 & 5.3 & 12.6 & $A o, B t, M t, S g$ \\
\hline Creag Meagaidh & NN451885 & 1 & 600 & 23 & 4.0 & 15.5 & Ao \\
\hline Coire Ardair & NN438878 & 1 & 700 & 25 & 3.7 & 14.2 & $\begin{array}{l}A o, B t, M t, M w \\
P c\end{array}$ \\
\hline Alladale & NH409882 & 2 & 300 & 20 & 5.8 & 14.0 & $B t, M t$ \\
\hline Geal Charn & NN575982 & 2 & 600 & 20 & 4.7 & 12.5 & $A o, B t, P p$ \\
\hline Corserine & NX515868 & 2 & 450 & 24 & 5.3 & 10.9 & $S g$ \\
\hline Ben More Coigach & NC105050 & 3 & 300 & 25 & 5.9 & 14.8 & $B t, B p, H h, M t$ \\
\hline Glenfinnan & NM904845 & 3 & 200 & 26 & 6.8 & 12.0 & $A o, B t, M t, S g$ \\
\hline
\end{tabular}


Table 2. Mean growth (g dry mass as absolute increase over the experimental period) at sites where Herbertus hutchinsiae was transplanted, north-west Scotland. Category 1, sites within species' current range; category 2, sites outside current range; category 3, sites where species has declined. $P$-value for growth indicates significance of difference from initial biomass (paired t-test).

\begin{tabular}{lcll}
\hline Site name & Site category & Mean growth $(g)$ & $\boldsymbol{P}$-value \\
\hline Cul Beag & 1 & $1.19 \pm 0.24$ & $<0.001$ \\
Creag Dubh & 1 & $1.49 \pm 0.14$ & $<0.001$ \\
Creag Meagaidh & 1 & $1.20 \pm 0.20$ & $<0.001$ \\
Coire Ardair & 1 & $1.10 \pm 0.19$ & $<0.001$ \\
\hline Alladale & 2 & $1.45 \pm 0.11$ & $<0.001$ \\
Geal Charn & 2 & $0.58 \pm 0.16$ & $<0.01$ \\
Corserine & 2 & $0.41 \pm 0.19$ & $<0.05$ \\
\hline Ben More Coigach & 3 & $0.65 \pm 0.20$ & $<0.01$ \\
Glenfinnan & 3 & $0.62 \pm 0.13$ & $<0.001$ \\
\hline
\end{tabular}


Table 3. Environmental variables (mean \pm SE) for each site category in a transplantation experiment of Herbertus hutchinsiae, north-west Scotland. Category 1, sites within species' current range; category 2, sites outside current range; category 3 , degraded sites where species has declined. Letters indicate significant differences between site categories $(P<0.05)$, assessed by Mann Whitney test.

\begin{tabular}{|c|c|c|c|c|c|c|c|c|c|c|}
\hline \multirow{2}{*}{$\begin{array}{c}\text { Site } \\
\text { category }\end{array}$} & \multirow{2}{*}{$\begin{array}{c}\text { Dwarf } \\
\text { shrub cover } \\
(\%)\end{array}$} & \multirow{2}{*}{$\begin{array}{l}\text { Bryophyte } \\
\text { cover }(\%)\end{array}$} & \multirow{2}{*}{$\begin{array}{l}\text { Graminoid } \\
\text { cover }(\%)\end{array}$} & \multirow{2}{*}{$\begin{array}{r}\text { Vegetation } \\
\text { height }(\mathrm{cm})\end{array}$} & \multirow{2}{*}{$\begin{array}{c}\text { Temperature } \\
\text { July }\left({ }^{\circ} \mathbf{C}\right)\end{array}$} & \multirow{2}{*}{$\begin{array}{c}\text { Oceanicity } \\
\text { index }\end{array}$} & \multicolumn{4}{|c|}{ Proportion of occurrence } \\
\hline & & & & & & & Liverworts & Algae & Overgrown & Plant litter \\
\hline 1 & $48.9 \pm 1.9 a$ & $38.3 \pm 1.7$ & $13.0 \pm 1.5 a$ & $19.1 \pm 1.0 a$ & $10.1 \pm 0.6$ & $14.0 \pm 0.6$ & $0.32 \pm 0.12$ & $0.09 \pm 0.02$ & $0.36 \pm 0.06$ & $0.04 \pm 0.02$ \\
\hline 2 & $39.6 \pm 2.0 b$ & $42.6 \pm 2.2$ & $17.8 \pm 2.2 a$ & $22.8 \pm 0.8 b$ & $11.0 \pm 0.4$ & $12.5 \pm 0.9$ & $0.35 \pm 0.18$ & $0.04 \pm 0.04$ & $0.31 \pm 0.13$ & $0.14 \pm 0.07$ \\
\hline 3 & $35.2 \pm 2.3 b$ & $38.3 \pm 2.1$ & $26.3 \pm 1.8 b$ & $14.1 \pm 0.9 c$ & $11.7 \pm 0.5$ & $13.4 \pm 1.4$ & $0.30 \pm 0.10$ & $0.35 \pm 0.18$ & $0.33 \pm 0.30$ & $0.13 \pm 0.10$ \\
\hline
\end{tabular}




\section{Figure captions}

Figure 1. Distribution map (10x10 km squares; small circles) of Herbertus hutchinsiae records in Scotland (Shetland Islands not shown), with the experimental sites for transplantation of $H$. hutchinsiae marked. Triangles: sites within the current range (1 Cul Beag; 2 Creag Dubh; 3 Creag Meagaidh; 4 Coire Ardair). Circles: sites outside the current range (5 Alladale; 6 Geal Charn; 7 Corserine) and crosses: sites where H. hutchinsiaehas declined (8 Ben More Coigach; 9 Glenfinnan).

Figure 2. Increase in biomass of transplanted Herbertus hutchinsiae bundles after 14 months, in different site categories in north-west Scotland: Category 1, sites within species' current range; category 2, sites outside current range; category 3, sites where species has declined. Mean growth (g dry mass) \pm SE. Letters indicate significant differences $(P<0.03)$.

Figure 3. Scatter plot diagram showing the relationship between initial biomass and change in biomass (g) of transplanted Herbertus hutchinsiae bundles. ***, $P<0.001$.

Figure 4. Species distribution model of Herbertus hutchinsiae in the British Isles. 'TSAbackground' continuous model, showing presences used to generate the model (white dots), as well as the transplant localities. Habitat suitability increases from pale blue to green to red. Black dots: sites within the current range of the species; green triangles: sites outside current range; red squares: sites where the species has declined. 


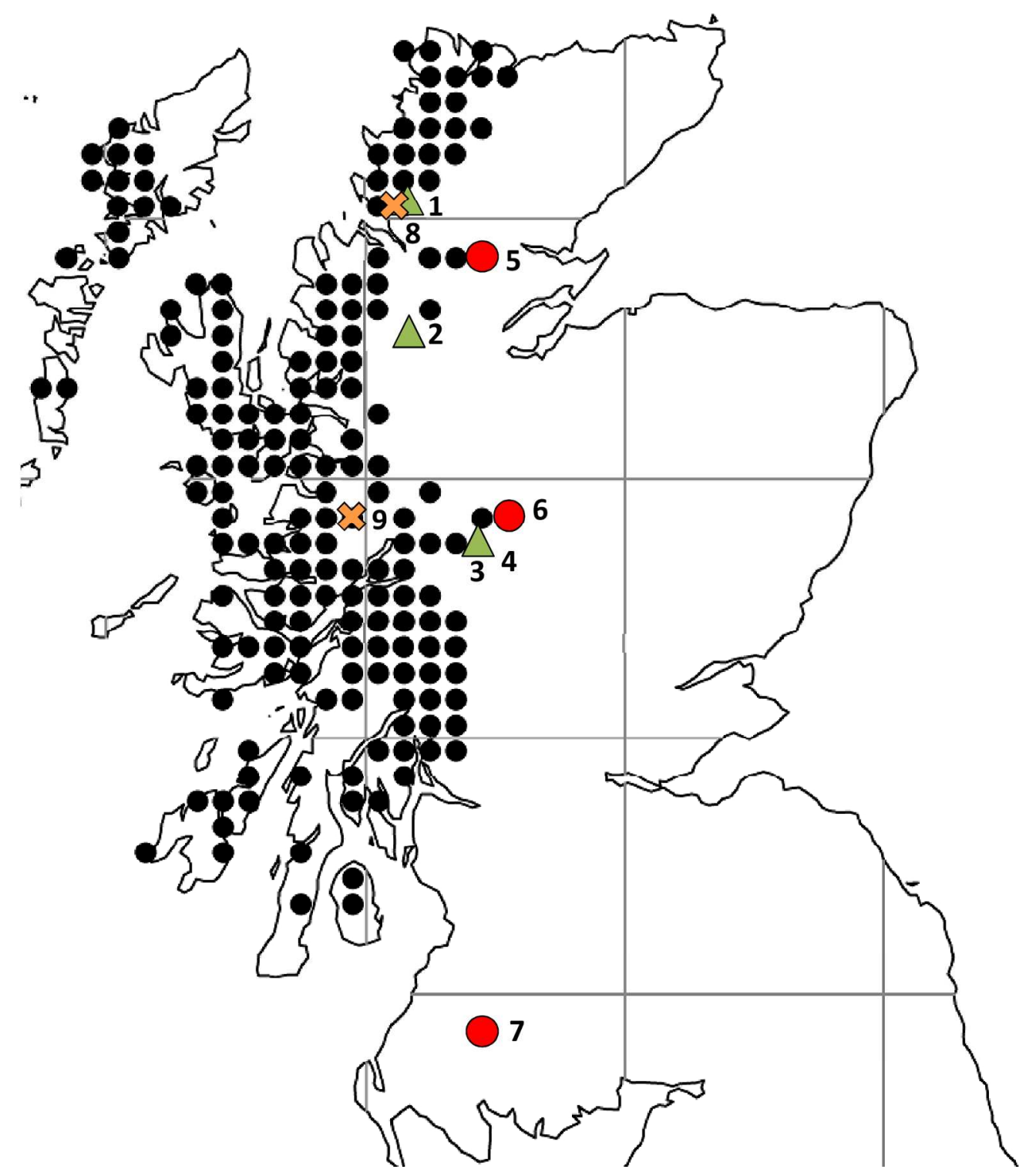

Distribution map (10x10 km squares; small circles) of Herbertus hutchinsiae records in Scotland (Shetland Islands not shown), with the experimental sites for transplantation of $\mathrm{H}$. hutchinsiae marked. Triangles: sites within the current range (1 Cul Beag; 2 Creag Dubh; 3 Creag Meagaidh; 4 Coire Ardair). Circles: sites outside the current range (5 Alladale; 6 Geal Charn; 7 Corserine) and crosses: sites where H. hutchinsiaehas declined (8 Ben More Coigach; 9 Glenfinnan). $160 \times 189 \mathrm{~mm}(300 \times 300 \mathrm{DPI})$ 
Increase in biomass of transplanted Herbertus hutchinsiae bundles after 14 months, in different site categories in north-west Scotland: Category 1, sites within species' current range; category 2, sites outside current range; category 3 , sites where species has declined. Mean growth ( $g$ dry mass) \pm SE. Letters indicate significant differences $(P<0.03)$.

$71 \times 40 \mathrm{~mm}(300 \times 300 \mathrm{DPI})$ 


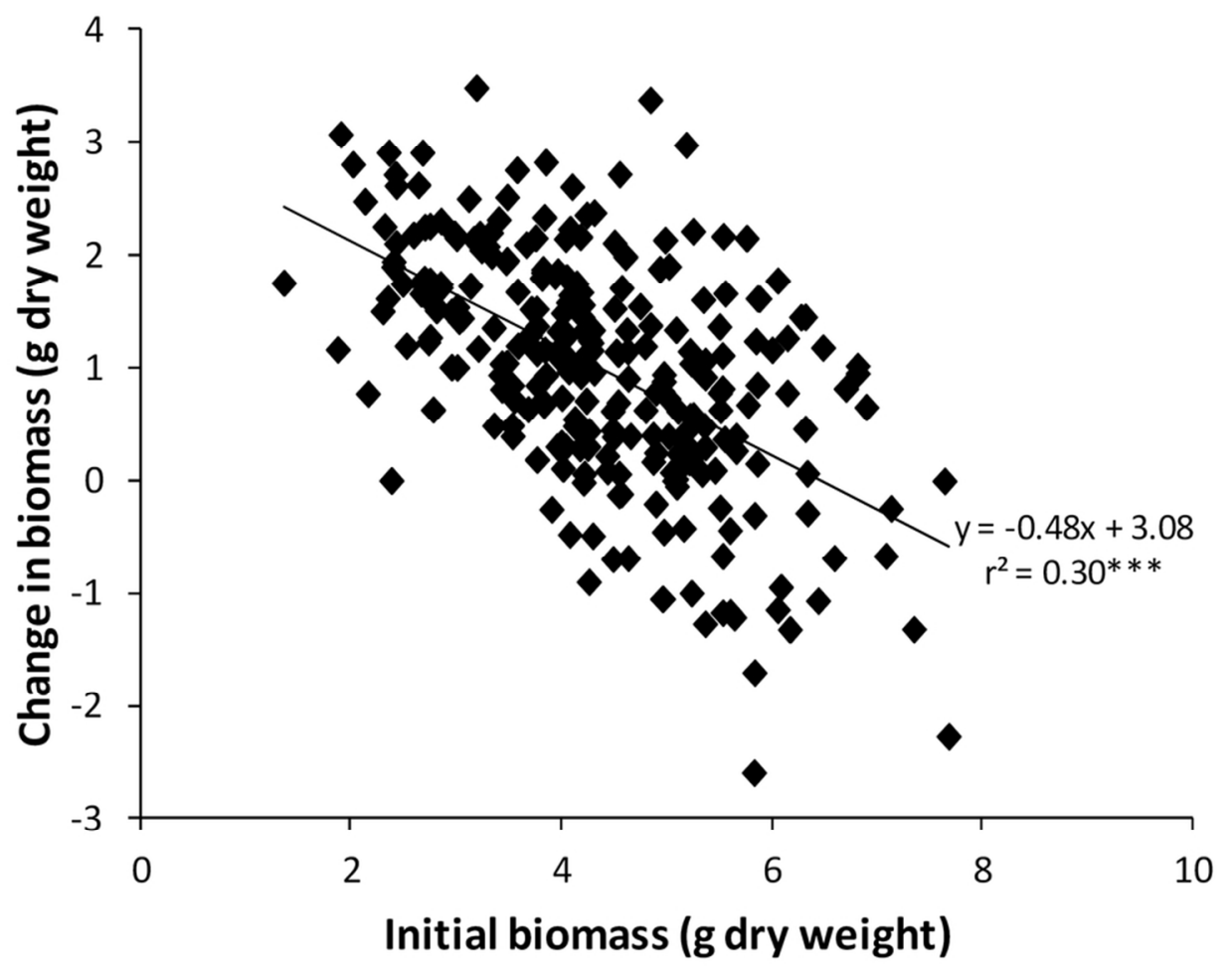

Scatter plot diagram showing the relationship between initial biomass and change in biomass $(\mathrm{g})$ of transplanted Herbertus hutchinsiae bundles. $* * *, \mathrm{P}<0.001$. $87 \times 64 \mathrm{~mm}(300 \times 300$ DPI $)$ 
Species distribution model of Herbertus hutchinsiae in the British Isles. 'TSA-background' continuous model, showing presences used to generate the model (white dots), as well as the transplant localities. Habitat suitability increases from pale blue to green to red. Black dots: sites within the current range of the species; green triangles: sites outside current range; red squares: sites where the species has declined. $156 \times 154 \mathrm{~mm}(300 \times 300 \mathrm{DPI})$ 